aparte de los nombres ya mencionados, los de José Casado del Alisal, Alexis Vera (y Estaca), José Carbonero Moreno (sic), Salvador Sánchez Barbudo, Manuel Ramírez Ibáñez, A. Ferrant (como no se dan otros detalles, con la mayor probabilidad Alejandro Ferrant Fischermans), y $\mathrm{F}$ (rancesc) Masriera. Especial elogio merecen los acuarelistas españoles, aunque sin darse a saber nombres, que sí se dan cuando se comentan los italianos. Prestaré atención a las opiniones de la crítica checa en alguna otra oportunidad (La fortuna crítica de pintores españoles, en checo).

En resumen, puede decirse que el lector checo estaba al tanto de lo que ocurría en el siglo XIX en el arte español casi más que hoy en día.

PAVEL ŠTĚPÁNEK

\title{
UN INÉDITO DE BARTOLOMÉ ROMÁN
}

En 1983 los profesores Angulo Íñiguez y Pérez Sánchez publicaron un estudio sobre el pintor Bartolomé Román. Además de aportar numerosos datos biográficos, ofrecen un catálogo de las obras entonces conocidas '.

Nacido en Montoro (Córdoba) en torno a 1587, recaló en Madrid, donde se le localiza realizando distintas obras en las que advierten los críticos la influencia de Vicente Carducho.

En la biografía del pintor hay una nota descollante: su relación y amistad con distintas órdenes religiosas, lo que explicaría la temática principal de su producción artística. El propio Bartolomé Román profesó en la Tercera Orden de San Francisco; de su matrimonio con María Teves nació un hijo que profesó entre los carmelitas, fr. Luis Román, quien aparece como testamentario de su padre ${ }^{2}$.

Con posterioridad a la publicación del elenco de obras localizadas por los profesores citados, han aparecido otras: «un gran cuadro monástico en una parroquia egabrense, una santa reina subastada y vendida por la casa Durán, de cuerpo entero... y un San Benito de colección particular, genial como toda su obra» ${ }^{3}$.

A la altura del año 1630 Bartolomé Román se encontraba en momento de gran inspiración. Justamente de este año hemos encontrado un lienzo que se conserva en colección particular.

Mide aproximadamente 0,65 × 0,50 m. Representa, creemos, a San Francisco de Asís. Una pequeña llaga en la mano izquierda con la que sostiene el Crucifijo, así parece indicarlo. Existe un rasgo iconográfico que recuerda a San Pedro de Alcántara, como podría ser un ala de paloma (?) en la parte alta de la derecha.

Al dorso, como puede apreciarse en la fotografía reproducida se lee:

$$
\text { Bart }{ }^{\text {me }} \text { Román, pintó } M^{d} 1630 .
$$

Como hipótesis muy probable se sugiere que la firma auténtica se encuentra oculta por una tela que se fijó al lienzo original. Así nos lo indicó, en conversación particular, el profesor

\footnotetext{
1 D. Angulo Íñiguez y A. E. Pérez Sánchez, Pintura madrileña del segundo tercio del s. XVII, Madrid, 1983, 313-338. En 1974 publicó el testamento del pintor Trinidad de Antonio Sáenz (AEA 47 [1974], 405 ss.).

${ }^{2}$ D. Angulo Íñiguez y A. E. Pérez Sánchez, Pintura madrileña, 313 ss. Fr. Luis Román, figura conventual del convento de carmelitas de Valdemoro en 1638. (Pablo María Garrido, O. Carm., El solar carmelitano de San Juan de la Cruz. Los conventos de la antigua provincia de Castilla [1416-1836], 318).

3 José Valverde Madrid, Bartolomé Román, en Crónica de Córdoba y sus pueblos, V, Córdoba, 1998, 470. Ignoramos si han aparecido otras obras.
} 



Bartolomé Román: San Francisco de Asís (?). Colección particular. 
Pérez Sánchez. En cualquier caso y según dicho profesor, se trataría de una obra que efectivamente pertenece a Bartolomé Román.

Por nuestra parte nos limitamos exclusivamente a darlo a conocer, aunque no ocultemos, la admiración que produce cuando se contemplan detenidamente todos sus pormenores.

\section{B. VelASCO}

\section{MAESTROS Y CANTEROS EN LAS OBRAS DEL MONASTERIO DE NUESTRA SEÑORA DE LA ASUNCIÓN (ALMAGRO)}

El monasterio de Nuestra Señora de la Asunción en Almagro acogió en el pasado a una comunidad femenina de la Orden de Calatrava. Según los distintos autores que han tratado el tema, la fundación de esta casa estuvo directamente relacionada con los piadosos deseos del Comendador Mayor de la Orden, Don Gutierre de Padilla. Este personaje mandó levantar un hospital en la localidad manchega, pero el proyecto era de tal envergadura que el Capítulo General celebrado en 1523 decidió modificarlo, ordenándose la construcción de un monasterio y que éste conviviese con un hospital de menores dimensiones ${ }^{1}$.

El valor de este conjunto monumental es incuestionable ya que nos encontramos ante un gran ejemplo de nuestra arquitectura del siglo xvi. Sin embargo, su relevancia en el plano artístico no se ha visto recompensada con un estudio en el que se analicen de forma pormenorizada los distintos aspectos de su fábrica. Si nos centramos en el problema que ahora nos interesa, es decir, en el de los artífices que trabajaron en este edificio, nos encontramos con un panorama prácticamente virgen ya que, hasta el momento, no se había recurrido de forma sistemática a las fuentes documentales. Contábamos, tan solo, con una escueta referencia a Enrique Egas el Mozo fechada en $1564^{2}$ y con una breve mención a la figura de un maestro poco conocido, el maestro Balbás, que estaría relacionado con las obras realizadas en el monasterio durante los primeros años del siglo XVI, concretamente en $1523^{3}$. Para remediar en lo posible esta situación, nuestro trabajo aporta varios datos de gran importancia sobre los artistas que trabajaron en la fábrica del edificio, datos que hemos encontrado al analizar dos fuentes que habían permanecido inéditas hasta ahora ${ }^{4}$.

El primer documento que vamos a utilizar está fechado en 1546. Se trata de la visita realizada al monasterio por el prior del Sacro Convento de Calatrava y por frey Francisco Carrillo de Guzmán, comendador de Vallaga. Entre la documentación generada por los autos que se llevaron a cabo durante esta visita nos encontramos con un pliego fechado el 20 de diciembre de 1544 en el que se recogen los nombres de cinco canteros que trabajaron ese año en las obras del edificio, especificando la labor que realizaron y la cantidad que recibieron por su trabajo. Lucas Mateo es el primer maestro al que se hace referencia, afirmando que cobró 2.400 maravedís por labrar doze varas de perpiaños para los arcos a presçio cada vara de a dozientos maravedis. A continuación se menciona a Francisco de Jerez, que percibió 2.200 maravedís por realizar otras once varas de perpiaños, y a Gabriel Romano, que cobró 1.700 maravedís por

\footnotetext{
I Díez de Baldeón, C.: Almagro. Arquitectura y sociedad, Toledo, 1993, p. 153.

2 Díez de Baldeón, C.: op. cit., p. 160.

3 Saínz Magaña, E. y Herrera Maldonado, E.: «Arte Moderno» en Ciudad Real y su provincia, Tomo III, Sevilla, 1996, p. 102.

4 Archivo Histórico Nacional, Ordenes Militares, Archivo Judicial de Toledo, pleito 43.132. Bajo esta signatura se hallan catalogados varios libros manuscritos que contienen distinta información sobre el convento.
} 